\title{
A case of idiopathic arterial calcification of infancy diagnosed at autopsy
}

\author{
A Dayapala ${ }^{1}$, I L Rathnayake ${ }^{1}$, P Pethiyagoda ${ }^{2}$ \\ Ceylon Medical Journal 2016; 61: 137-138～DOI: http://doi.org/10.4038/cmj.v61i3.8354
}

\section{Introduction}

Neonatal deaths pose challenges for parents, clinicians and forensic practitioners alike. Detailed histories, clinical and investigative findings, autopsies and ancillary investigations can be helpful in diagnosis. Even some rare genetic conditions can be diagnosed with commonly available diagnostic tools such as histology with Haematoxylin and Eosin staining. Once such inherited conditions are diagnosed, genetic counseling can be done to prevent recurrence of neonatal deaths. Idiopathic arterial calcification of infancy is an autosomal recessive condition characterised by calcification of internal elastic lamina of medium and large arteries causing sudden deaths in infancy [1-3].

\section{Case report}

An 11-day old male infant, fourth child of a second degree consanguineous marriage, developed poor sucking and excessive crying. There was difficulty in breathing and vomiting when child was admitted to hospital. Thereafter the infant developed cyanosis with features of circulatory failure and died after 5 hours despite treatment with antibiotics, inotropic agents and ventilatory support.

The baby had been born after a normal vaginal delivery at term without any antenatal or peripartum complications. The first child of the family, a girl, has also had died 21 days after birth without any obvious cause. The patients have two more daughters, 6 years and 3 years old.

At autopsy of the body of the deceased infant weight $3200 \mathrm{~g}$ and was cyanosed but devoid of dysmorphic features, icterus or pallor. The heart, coronary vessels and great vessels were macroscopically unremarkable except an anatomically patent ductus arteriosus. The airway was clear, but the lungs were heavy and sinking in water. The liver and spleen were congested and friable. The brain, meningies, pancreas, kidneys and bladder, and the gastrointestinal tract were macroscopically unremarkable. There were bilateral adrenal haemorrhages.

Right and left pleural cavities contained $2 \mathrm{ml}$ and $5 \mathrm{ml}$ of straw coloured effusion respectively. The pericardial cavity contained $7 \mathrm{ml}$, and the peritoneal cavity, $10 \mathrm{ml}$ of similar fluid.
Calcification of internal elastic lamina and thickening in subintimal tissues of arteries with congestion of the lung parenchyma was noted in the $\mathrm{H}$ \& $\mathrm{E}$ stained sections (Figure 1). There was no microscopic evidence of pulmonary hypertension, aspiration or pneumonia. The coronary vessels showed similar microscopic changes with ischemic and early fibrotic changes of myocardium (Figure 2). Arteries in the pancreas, kidneys, and ductus arteriosus also had similar changes.

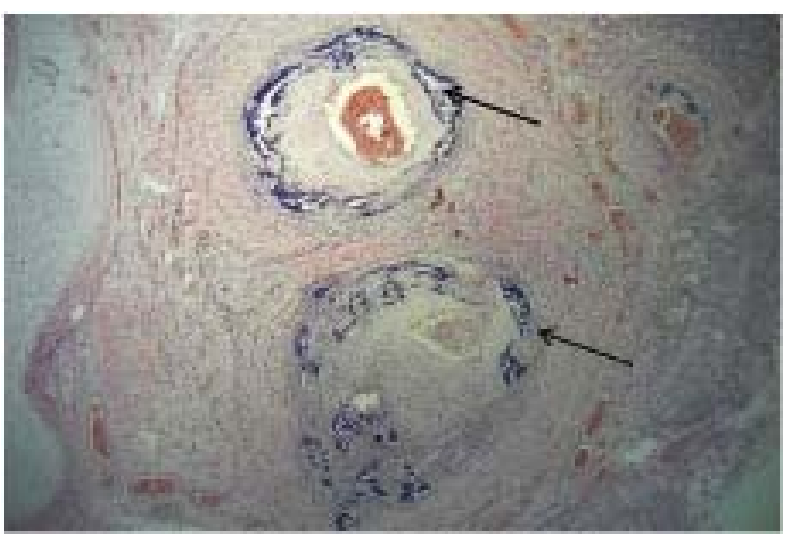

Figure 1. Calcification of internal elastic lamina (arrow) with sub-intimal thickening of pulmonary arteries (H\&E).

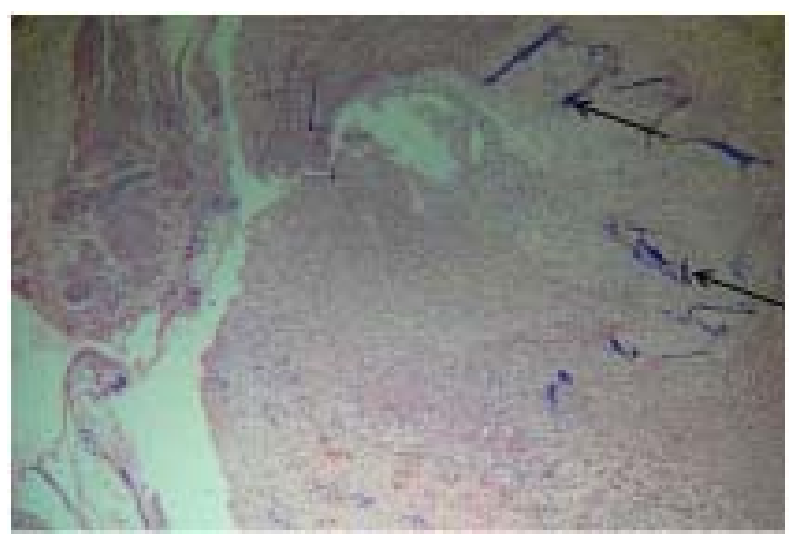

Figure 2. Coronaries with calcification of internal elastic lamina (arrow) and ischemic changes and fibrosis of myocardium (H\&E).

${ }^{1}$ Judicial Medical Unit and ${ }^{2}$ Paediatric Unit, Base Hospital, Avissawella, Sri Lanka.

Correspondence: AD, e-mail: <adayapala@yahoo.com>. Received 5 January and revised version accepted 31 May 2016.

This is an open-access article distributed under the terms of the Creative Commons Attribution License, which permits unrestricted use, distribution, and reproduction in any medium, provided the original author and source are credited. 


\section{Discussion}

Perinatal and neonatal deaths pose a diagnostic challenge as the causes and complexity of findings can be limitless [3-5]. Careful analysis of case histories, auto-psies to exclude trauma, aspiration, congenital abnor-malities and foci of infections, and ancillary investigations may yield a positive diagnosis [3,4].

In this case, consanguinity and the previous neonatal death gave a clue to the possibility of an inherited condition leading to the death. Macroscopically trauma, aspiration, congenital abnormalities and septic foci could be excluded. Facilities for screening of metabolic disorders were not freely available. But histological examination of tissues with H\&E staining was useful in the diagnosis of this case.

Idiopathic arterial calcification of infancy is a rare inherited condition characterised by extensive calcification of internal elastic lamina of large and medium sized arteries. It is accompanied by narrowing of arterial lumen by thickened of sub-intimal tissues $[1,2,6,7]$. Characteristic histological features and the presentation are useful in differentiating it from other conditions causing calcification of tissues in neonates such as hyper-vitaminosis D, parathyroid abnormalities, intrauterine infections and renal diseases. [1,7]. Refractory cardiac failure is common [1,6,7]. Intrauterine diagnosis of this condition is possible with advanced radiological techniques $[1,6]$.

Idiopathic arterial calcification of infancy with recurrent neonatal deaths has been reported in consanguineous families $[1,2,7]$. This condition can be complicated by severe systemic hypertension and myocardial ischaemia. Later the lamina can rupture leading to occlusion of the arteries. Deaths due to myocardial infarction can occur during the first 6 months of life [2]. Medical management of this condition includes drugs to reduce soft tissue calcification, inflammation and hypertension $[1,6]$.

Since the inheritance is autosomal recessive, con- sanguinity, as seen in this case, increases the risk of developing the disease in future pregnancies. Early diagnosis and genetic counseling are necessary for the prevention of recurrent neonatal deaths as well as the future well being of the siblings $[1,2,6]$.

\section{Consent}

Child's parents gave informed written consent for this publication.

\section{Conflicts of interest}

There are no conflicts of interest.

\section{References}

1. Nael A, Siaghani PJ, Chen D, Romansky SG, Shane L. Idiopathic Infantile Arterial Calcification: A Possible Cause of Refractory Cardiopulmonary Failure in Infancy. Case Reports Pathol 2014, Article ID 189850.

2. Sundaram S, Kuruvilla S, Thirupuram S. Idiopathic arterial calcification of infancy - a case report. Images Paediatr Cardiol 2004; 6: 6-12.

3. Wainwright HC. My approach to performing a perinatal autopsy. J Clin Pathol 2006; 59: 673-80.

4. Gilbert-Barness E, Debich-Spencer DE, Handbook of Pediatric Autopsy Pathology. Totowa, New Jersey. Humana Press. 2005.

5. Jehan I, Harris H, Salat S, et al. Neonatal mortality, risk factors and causes: a prospective population-based cohort study in urban Pakistan. Bull World Health Organ 2009; 87: 130-8.

6. Greenberg B, Gibsonz J. New Findings in Idiopathic Arterial Calcification of Infancy Detected by MDCT.AJR Am J Roentgenol 2005; 185: 530-2.

7. Bird T.Idiopathic arterial calcification in infancy. Arch Dis Child 1974; 49: 82-9.

\section{Information for Authors}

Information to authors on how to send an article to the CMJ is not published in

this (September) issue due to lack of space.

The information is available at the CMJ website -

http;//www.sljol.info/index.php/CMJ/index 